\title{
EFFECTS OF COPPER AND OIL IN THE CONTROL OF SIGATOKA BANANA LEAF SPO'T ${ }^{1}$ )
}

\author{
D. TOLLENAAR \\ Bilthoven (Netherlands)
}

\begin{abstract}
SUMMARY
Differences between oil and copper re their action against Sigatoka disease are discussed.
\end{abstract}

1. Because of its low surface tension immediately after being deposited, oil flows out in a thin film on the leaf surface and penetrates into the leaf, where it is able to check the further development of the fungus if it is in an early stage. Its action is rapid and in a certain respect curative.

By disappearing for the greater part from the leaf surface and by becoming assimilated by the plant, oil cannot have a lasting effect. For that reason spraying cycles must be short and even during the dry season spraying may not be completely abandoned.

2. The scorching effect often observed after oil spraying, can be mainly eliminated by the use of specific oils. But all oils effective against the disease also seem to be harmful to the plant by interfering with the normal metabolism, which effect is cumulative. It leads to earlier aging and easier threading of the leaves and with a smaller number of active green leaves per plant, growth and production are effected. In Ecuador, with its favourable conditions for the growth of bananas, the plants have more active green leaves than in most other countries and that may be the reason for the fact that this depressive effect on production has not (yet ?) been reported there.

3. The action of good sticking copper can only be a protective one against Sigatoka disease, because it does not enter into the leaf in sufficient quantities. Therefore it is never curative, but staying for months on the leaf surface and going into ionic solution when the leaf is wetted, it makes the water toxic every time, that Sigatoka conidia would get the right condition to germinate, which is checked, however, by these minute amounts of copper. Thus copper has a lasting protective effect; spraying cycles can generally be longer than with oil. Used in the right way, copper is not harmful to bananas, sometimes it has a stimulating effect. Its controlling effect is cumulative, in the course of time the amounts to be added can be reduced; it is possible to interrupt copper spraying during the dry season, without risking control.

4. Oil is a great help when Sigatoka control is lost, but copper is the right fungicide to use once that control has been regained, in order to keep it under control in the safest way.

5. The technique to add an active spray to a banana plantation is much easier with oil than with copper. With oil there is no need to aim at a regular distribution of the liquid on a leaf because it immediately redistributes itself. But in order to achieve a good sticking and effective copper coverage the deposition must take place as an even, dense pattern of small droplets, that remain separate and do not flow together or redistribute. To achieve this a special spraying technique is necessary, using droplets of a special size $(50-100 \mu)$, with a certain surface tension and arriving with a certain speed and in sufficient numbers at the leaf surfaces to be covered. It is easy to achieve this with specially designed ground machinery. Spraying from the air has many advantages, but working from a larger distance more liquid and more copper will have to be sprayed than with such a ground machine, in order to achieve the same good coverage.

6. As a result of an experiment and of practical experience it has become clear that abandoning oil spraying in Ecuador during the dry season leads to an intensifying of Sigatoka. On the other hand with copper spraying this interruption is possible without risking future control.

1) Received for publication August 22, 1960. 


\section{INTRODUCTION}

For 20 years Bordeaux high volume spraying was successfully used to control Sigatoka in Central America. With approx. 3-weekly cycles of $2000 \mathrm{l}$ per hectare and $5 \mathrm{~kg}$ copper metal per spray, control was fully effective.

Automatic mist-spraying with Banacobre was introduced in 1954 in Ecuador (TollenaAr, 1955) and in 1956 with the Cameroons Development Corporation, using a specially built tower sprayer, the so called "Giraffe". Like in the case of high volume Bordeaux spraying full control was achieved with 3-weekly cycles; liquid consumption, however, was reduced to 1001 and metal copper to $1 \frac{1}{2} \mathrm{~kg}$ per hectare per spray (afterwards liquid consumption has been reduced to $25 \mathrm{l} / \mathrm{ha}$ ).

French research in the Caribbean (Guyot, c.s., 1953, 1954) developed oil spraying from air planes (helicopter or fixed wing aircraft), which further reduced liquid consumption to approx. 8-12 l per ha. Control seemed satisfactory; a special feature of oil was that it showed a certain curative effect. Because of its simplicity (no ground machines; hardly no labour involved) oil spraying rapidly found its way in C. America and Africa. But in most cases after a year of oil spraying detrimental effects of oil became apparent, which lead to abandoning oil spraying (United Fruit, 1959) and now the problem reverts : how to combat Sigatoka effectively in the cheapest and simplest way?

\section{Advantages and disadvantages of THE USE OF OIL AND COPPER}

When I observed the effects of oil spraying for the first time in Jamaica on the Lacatan variety in February 1956, three main features became immediately apparent $(\mathrm{a}-\mathrm{c})$.

a) Oil rapidly flows out in a film over the leaf surface, because it redistributes itself immediately, owing to its low surface tension. This is one of the big advantages of oil. With copper we must achieve a regular drop distribution on all leaves by a special spraying technique, that is bound to strict conditions : drops of $50-100 \mu$ diameter with a special surface tension must reach the leaf in sufficient numbers carried by air that, when reaching the leaf, must have a velocity of $5 \mathrm{~m} /$ second!

b) Oil penetrates rapidly into the leaf and disappears for a great deal from the leaf surface. Its penetration brings the oil into contact with the fungus inside the leaf; but its disappearance from the surface reduces its protective action.

The penetration of oil becames apparent by a limpid colour of the leaves with transmitted light and a dull colour with light falling on the leaves (Froeschel, 1951). Its penetration is a consequence of the low surface tension of oil, for which reason it is added to insecticides in order to stimulate their entering into the trachae (WILcozon \& HarTzell, 1931). Oil also penetrates through plant cuticulae and it may spread throughout the whole plant, even into the root tissue, as was proved by Knight, Chamberlain and Samuels (1929).

c) A scorching effect of oil on leaves and fruit was visible. This scorching effect has since then been eliminated for the greater part by the use of specific oils (with a high unsulphonable mineral residue; PEArson, 1958). But apart from these visible effects other damage to the metabolism of plants had to be feared, e.g. from the experience gained in Citrus with spraying 
small amounts of oil (Thompson, Griffith \& Sites, 1951) and because of the fact that oils are well known weedkillers. On the other hand copper added in small amounts has often been recorded for its stimulating effect on growth and production (van Alpien, 1957 ; TollenaAk, 1959).

One of the first harmful effects of oil of this kind that became apparent was the reduction of the life time of the banana leaves; on the other hand the effect of copper has often been observed as to prolong the life of leaves (e.g. RaYNer, 1951). Because of that shorter life, there are fewer active green leaves per plant on an area sprayed with oil, which reduces growth, production, fruit weight and new sucker production. This is what has mainly stopped the use of oil, except in Ecuador.

\section{SOME EXPERIENCE IN ECUADOR WITH THE USE OF OIL}

It is a remarkable fact that this latter damage is not (yet) visible in Ecuador and oil spraying there is still in use on a large scale. In Ecuador only the Gros Michel variety is grown. Is it the type of oil used in Ecuador or are special climatic conditions responsible for this abnormal behaviour? It is unprobable that there is any type of spray oil that will have no detrimental

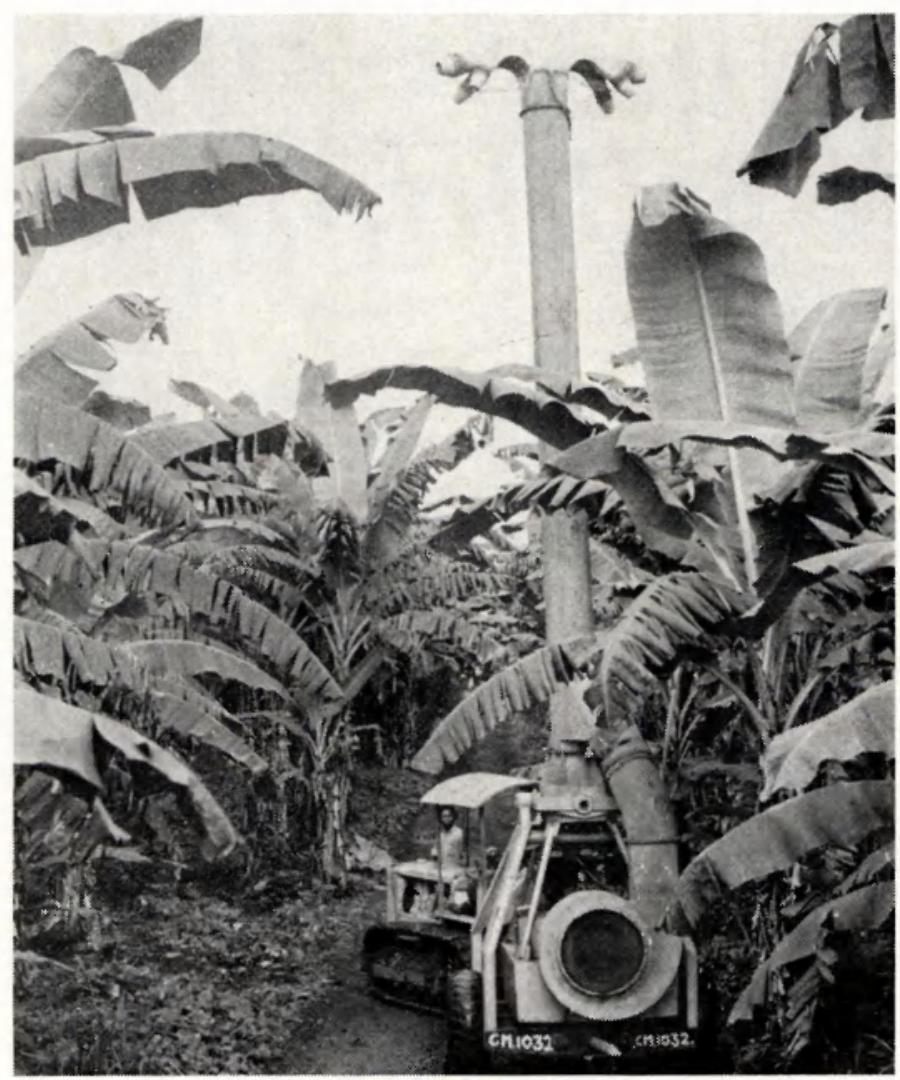

Fig. 1 "Giraffe" mist-blower spraylng gros michel bananas in apea of Cameroons DEVELOPMENT CORPORATION. NOTE THREADING OF LEAVES CAUSEd BY MODERATE WiND. 
effect; Price (1958) concluded from his laboratory experiments; that "all oils used for spraying are toxic to both host and pathogen to a greater or lesser degree." And United Fruit Research (1959) came to the same conclusion "that all known and tested oils are more or less damaging the plant, except those oils which do not control Sigatoka disease". But climate and soil of the Riverine Belt of Ecuador have special advantages for bananas, unique in the world (HARDY, 1960). There is practically no wind, the humidity is high and the soils are young volcanic ashes with a texture ideal for bananas. This together creates an enormous vigour and more green active leaves per plant than in any other country; besides, the leaves are hardly threaded because of the failing wind. With more active leaves per plant than anywhere else, the effect of oil damage might be reduced or might develop later (see fig. 1).

Changing over from oil to copper is in Ecuador no urgent problem, but with the experience elsewhere, Ecuador should be prepared to get such damage at a later moment, when the effect has accumulated.

Additional to this is another less satisfactory experience with oil spraying, which makes further research in Ecuador advisable, viz. that oil has shown to give less protection against conidia infection than copper.

\section{THE BETTER PROTECTING EFFECT OF COPPER COMPARED WITH OIL}

At Clementina, Ecuador Sigatoka broke out in a serious way in 1954, which called for immediate combatting. Thus in 1955 spraying was started on a commercial scale with Giraffe mist-blowers and Banacobre, as described by the author (TollenaAR, 1955). This got Sigatoka under some control in 1955, under better control in 1956 and in 1957 it practically disappeared from the areas sprayed in the former years. Then in the beginning of 1958 Clementina changed over to aerial oil spraying, because of its simplicity; in 1958 control was less ideal than it had been in 1957, in 1959 it became worse and in 1960 during the months April to June control was partly lost (see table 1).

Table 1 Sigatoka spotting at Clementina, Ecuador during April-June 1960. Average per mille spotting of 9 th leaf

\begin{tabular}{|c|c|c|c|c|c|c|}
\hline & & \multicolumn{2}{|c|}{ Copper spraying } & \multicolumn{3}{|c|}{ Oil spraying } \\
\hline & & 1956 & $\left.1957^{*}\right)$ & 1958 & 1959 & 1960 \\
\hline $\begin{array}{l}\text { April } \\
\text { May } \\
\text { June }\end{array}$ & 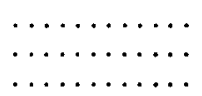 & $\begin{array}{r}9 \\
13 \\
12\end{array}$ & $\begin{array}{l}0 \\
0 \\
0\end{array}$ & $\begin{array}{r}15 \\
12 \\
6\end{array}$ & $\begin{array}{l}23 \\
36 \\
32\end{array}$ & $\begin{array}{l}55 \\
66 \\
68\end{array}$ \\
\hline
\end{tabular}

*) Same area as in 1956.

In another experimental block the result was exactly the same, e.g. in May 1957 there was no Sigatoka, in 1958 there was $33 \%$ spotting, in 1959 $36 \%$ and in $196079 \% 0$.

Copper spraying had a cumulating good effect on control : the effect of oil was just opposite.

For an explanation it must be mentioned that Clementina has a wet season during the first half of the year, but during the second half of the year there is practically no rain at all. For that reason spraying is concentrated between November and June. And it is exactly during the dry season, when spraying is abandoned, that the different effect of oil and copper appears. The first 
indication was obtained from a small trial, comparing oil and Banacobre in 8 alternative strips; spraying was executed with Giraffe.

Table 2 Experiment, comparing effect of oil and Banacobre Average per mille spotting of 9 th leaf

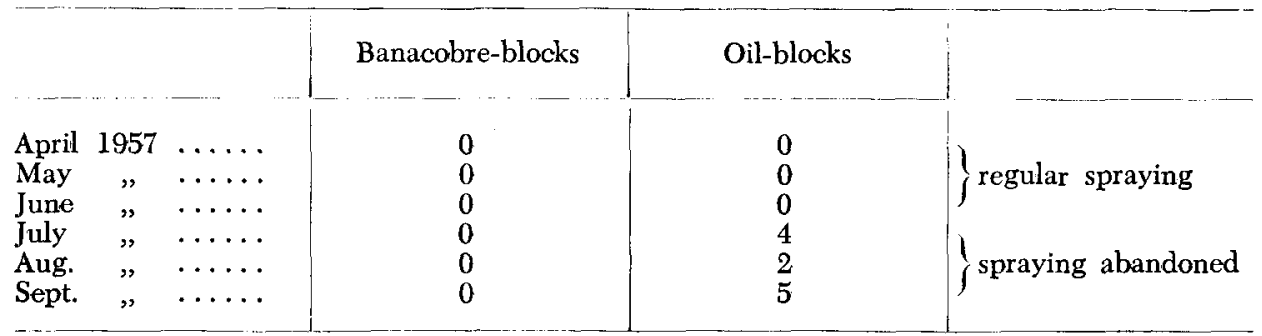

This spraying trial had been started in an area that was practically free from Sigatoka as a consequence of copper spraying during the 3 preceding years. Because of the dry season, spraying was interrupted on June 24th. Then immediately in July there developed some Sigatoka in the oil blocks, the copper blocks remained free. This was an indication that in the oil blocks some Sigatoka was dormant in the leaves, which developed when no fresh oil was added. This checks excellently with the result of laboratory experiments, carried out with oils by PRICE (1958): "In no case over the duration of the experiment did a culture die and this is strong evidence that spray oils act as fungistats like liquid paraffin and not as fungicides".

It is during the dry season when spraying is interrupted that Sigatoka builds up after oil spraying, because oil has no protective and no lasting effect. This can further be proved from the Sigatoka figures of the commercially sprayed areas at Clementina. Also there the difference between the effect of oil and copper became visible during the dry season, when spraying was interrupted (see table 3, showing how Sigatoka developed after June).

Table 3 Sigatoka spotting during dry season, when spraying was interrupted. Average par mille spotting of 9 th leaf

\begin{tabular}{|c|c|c|c|}
\hline & $\begin{array}{l}\text { After copper } \\
\text { spraying }\end{array}$ & After & ying \\
\hline & 1957 & 1958 & 1959 \\
\hline 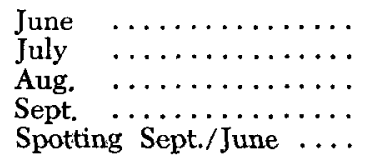 & $\begin{array}{l}7 \\
6 \\
5 \\
3 \\
-57 \%\end{array}$ & $\begin{array}{r}6 \\
7 \\
8 \\
17 \\
+183 \%\end{array}$ & $\begin{array}{c}36 \\
44 \\
62 \\
53 \\
+47 \%\end{array}$ \\
\hline
\end{tabular}

Oil acts rapidly; by penetrating it is able to check the development of the fungus when it is still in an early stage; it is not protective because it is not remaining on the surface and it loses its activity rapidly.

Copper, on the other hand, has no penetrative action; for that reason it cannot check the disease anymore once the fungus has entered into the leaf. But by sticking on the leaf surface it has a protective and a more lasting effect.

When an area has lost control, oil should be used until control has been regained; from then on it should be kept in that condition by spraying copper.

The cumulative controlling effect of copper spraying is clearly demon- 
strated from figures of commercially sprayed areas at Clementina in 1956 and 1957. One area (Area I) was pre-treated with copper in 1955, a second area (Area II) was for the first time pre-treated in 1956. After that pre-treatment and during further regular copper spraying Sigatoka spotting developed as shown in table 4.

Table 4 Sigatoka under Banacobre spraying Average per mille spotting of 9th leaf

\begin{tabular}{|c|c|c|c|c|c|c|}
\hline & & & AREA & I (pre-treated 1955) & AREA & II (pre-treated 1956) \\
\hline $\begin{array}{l}\text { Jan. } \\
\text { Febr. } \\
\text { March } \\
\text { April } \\
\text { May } \\
\text { June } \\
\text { July } \\
\text { August } \\
\text { Sept. }\end{array}$ & $\begin{array}{c}1956 \\
" \\
" \\
" \\
" \\
" \\
" \\
"\end{array}$ & 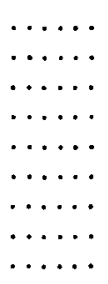 & $\begin{array}{r}9 \\
18 \\
2 \\
9 \\
13 \\
12 \\
10 \\
6 \\
3\end{array}$ & $\begin{array}{l}\text { Total Banacobre } \\
\text { used per hectare } \\
48 \mathrm{kgs}\end{array}$ & & \\
\hline $\begin{array}{l}\text { Jan. } \\
\text { Febr. } \\
\text { March } \\
\text { April } \\
\text { May } \\
\text { June } \\
\text { July } \\
\text { August } \\
\text { Sept. }\end{array}$ & $\begin{array}{c}1957 \\
" \\
" \\
" \\
" \\
" \\
" \\
"\end{array}$ & 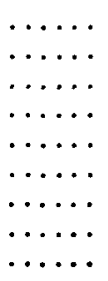 & $\begin{array}{l}0 \\
0 \\
0 \\
0 \\
0 \\
0 \\
0 \\
0 \\
0\end{array}$ & $\begin{array}{l}\text { Total Banacobre } \\
\text { used per hectare } \\
36 \mathrm{kgs}\end{array}$ & $\begin{array}{r}10 \\
6 \\
2 \\
3 \\
3 \\
17 \\
15 \\
11 \\
8\end{array}$ & $\begin{array}{l}\text { Total Banacobre } \\
\text { used per hectare } \\
48 \mathrm{kgs}\end{array}$ \\
\hline
\end{tabular}

Once Sigatoka is brought under control it is possible to reduce the amount of copper.

\section{How SHOULD THE SPRAYING OF COPPER BE EXECUTED?}

Oil is a big help when control is lost, but otherwise the use of copper is preferable, also in Ecuador, because of its lasting and protective control and its lacking of harmful effects.

It is unattractive to revert to high volume spraying. With low volume spraying the problem of a good distribution was solved with the Giraffe ground spraying machine (see fig. 2) and Banacobre-Sandoz was during the copper spray period at Clementina (1954-1957) the most active and best sticking copper available; it did not clog the pipes and had no corrosive effect. Since then Banacobre-Ol has been developed, which is an improved product for bananas, when high concentrations $(10-20 \%)$ are being used. But disadvantages of the Giraffe are: its heavy weight with its effect on the physical properties of some soils, the difficulties to use it in rolling, drained or newly cleared land and the possibility, which every ground machine has, that it might spread Panama disease if present. To-day a Giraffe could be constructed with about one tenth of the wheel pressure of the type used in 1955-1958.

Yet the advantages of aerial spraying remain obvious. In that connection it is useful to point out the difficulties in spraying copper successfully from the air. For a good understanding it is necessary to enter into details of the disease behaviour. 


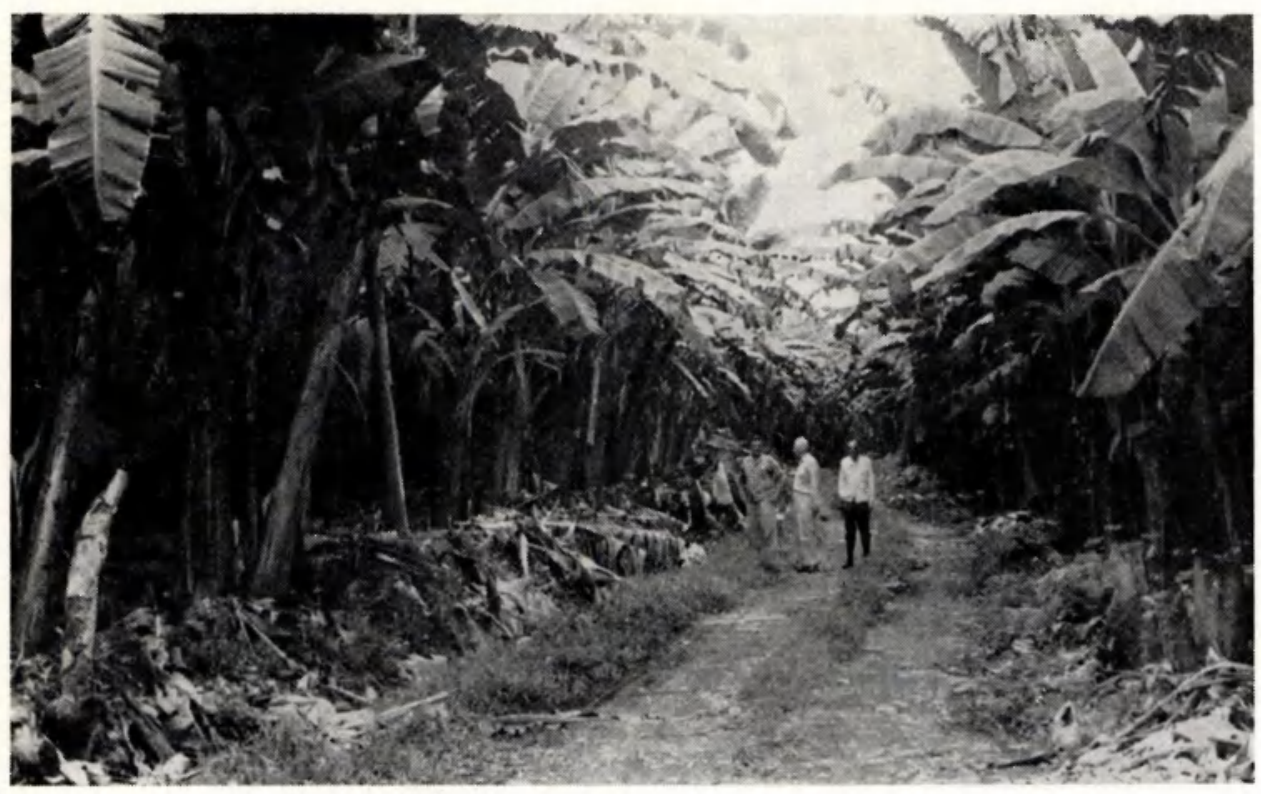

Fig. 2 Gros michel banana plantation in Ecuador. Note glowth vigour and extensive LEAF PRODUCtion AND LITTLE THREADING OF Leaves (hamdiy No WiNd).

Photo J. Holger Graffman.

Control of Sigatoka with copper is mainly based on the checking of the germination of water-borne conidia. Copper has no effect on the air-borne ascospores. Therefore as soon as these ascospores are being produced, which is mostly the case when leaf-spotting becomes intensive (LEACH, 1945), control with copper is lost. But once infection has been brought down to a low intensity, copper is the ideal fungicide. Conidia are only produced on older, spotted leaves, at least 5-6 weeks old; the coverage with copper on all such leaves has to be perfect. Infection preferably takes place in nature on the lower leaf surfaces of the two youngest leaves, but these lower leaf surfaces, also with the Bordeaux spraying technique, are not specially covered, which proves that the copper spraying technique is not mainly based on a protection against infection of unfurling susceptible leaves.

It is a common idea that it is necessary to spray the young leaves in order to protect them against infection. That this idea must be fundamentally wrong, is also proved by the simple fact that one is able to control Sigatoka with spraying cycles of $2 \frac{1}{2}$ to 3 weeks in light infected plantations. This means that notwithstanding a new leaf is produced per plant every 8-12 days, and notwithstanding the fact that most of these young susceptible leaves thus remain unprotected for more than one week, yet no infection takes place. Spraying of new leaves is first of all important from the point of view that it is the best moment to cover them regularly because they are not yet screened by other younger leaves. Later on when they are going to produce conidia, copper must be present to make the water toxic. Thus two things are fundamental for a good control in light infected areas :

a that all young leaves get on the upper leaf surface a dense regularly distributed pattern of copper, and 
b that this copper sticks to these banana leaves for a couple of months.

The difficulty to achieve this, is not presented by the Banacobre, that has all the properties needed, but by the technique of addition.

The Banacobre-OI has in high concentration the right surface tension on banana leaves. This is very important, because if the surface tension is too high the drops bounce off when they are blown on to the leaves. If on the other hand the surface tension is too low, the drop will be too flat and then it will spread and combine with other droplets and flow together along veins and leaf margins, dripping off partly. Thus the copper will partly be lost immediately and for the rest it will be mainly washed off by the first rain shower. The drops must stay separate because such separate small drops are resistant to rain wash. When rainwater or dew wet the leaf and conditions become favourable for germination of the conidia, copper ions go into solution, which checks their germination. In order to achieve such a regular drop pattern the outlet of the Giraffe spraying machine had to blow droplets of a size of $50-100 \mu$ with a definite air speed, at a distance of 5-10 metres on the young unfurling leaves. When - with an airplane - the distance becomes larger, more copper and more liquid will be needed to achieve the same regular dense pattern. Successful aerial copper-spraying will depend on blowing system, dropsize, low and systematic flying. But because of the greater distance probably about double the liquid and Banacobre will be needed compared with the Giraffe (viz. 25-40 litres of water and $2 \mathrm{kgs}$ Banacobre with the Giraffe). That stands against the disadvantages which every ground machine will present.

\section{REFERENCES}

Alphen, Th. G. van: Spraying crops with copper. Wageningen, 1957, 65 pp.

Froescher, P. : Neue Methoden der Blattinfiltration. La Cellule 54 (1951).

Guyot, H. and J. Cuillé: La lutte contre Cercospora Musae dans las bananeraies de Guadeloupe, essais de néblisation. Fruits d'Outremer 8 (1953), 525-532.

- -, - - : Les formules fongicides huileuses pour le traitement des bananeraies. Fruit d'Outremer 9 (1954), 269-288.

HARDY, F. : Report on a visit to the Riverine Belt of Ecuador. Interamer. Inst. of Agr. Sc., Turrialba, (1960), pp. 103.

LeACH, R. : Banana Leaf Spot on the Gros Michel variety in Jamaica. Kingston (1946), $118 \mathrm{pp}$.

Knight, H., J. C. Chamberlain and C. D. Samuel: On some limiting factors in the use of saturated oils as insecticides. Plant Physiology 4 (1929), 300-321.

Price, D.: The selection of oils for spraying against Spot disease of bananas. Tropical Agriculture 35 (1958), 225-228.

Pearson, A. J. A. : Banana spraying with mineral oils. Span 1, nr. 3 (1958), 2-4.

Rayner, R. W.: Tonic copper sprays. Monthly Bull. Coffee Bd Kenya 16 (1951), 212-213.

Thompson, W. L., J. T. Griffith and J. W. Sires: A comparison of oil emulsion and parathion for the control of scale insects on citrus. Proc. Florida State Hort. Soc. 64 (1951), 66-71.

TollenaAr, D.: The control of Sigatoka by mist-blowing with Banacobre-Sandoz. Neth. Journal of Agr. Science 3 (1955), 70-83.

- - : Increased cocoa production by foliar copper applioations as an effect additional to Witches' broom disease control. Tropical Agriculture 36 (1959), 177-188.

UNITED Fruit Research: Bordeaux-oil-bordeaux; the why's and wherefore's of current changes. Newsletter 6, no. 4 (1959), 1-8.

Wirlcoxon, F. and A. Hartzelc : Some factors effecting the efficiency of contact insecticides; surface forces as related to wetting and tracheal penetration. Contr. from the Boyce Thompson Inst. 3 (1931), 1-12. 